\title{
Greentelligence: Smart Manufacturing for a Greener Future
}

\author{
Xingyu $\mathrm{Li}^{1}$, Baicun Wang ${ }^{2^{*}}$, Tao Peng ${ }^{2}$ and Xun $\mathrm{Xu}^{3}$
}

\section{Introduction}

Global climate change has grown into one of the major concerns in global industrialization and economic development. Carbon dioxide $\left(\mathrm{CO}_{2}\right)$, one of the six Kyoto Protocol greenhouse gases (GHGs), is the most difficult to contain due to its closeness with energy generation and consumption [1]. With an earlier awareness of climate change, developed countries tended to displace the resource- and energy-intensive industries to other countries, thus emissions have not been reduced but relocated [2], which can be further magnified if production shifts to countries using carbon-intensive energy or low-energyefficient technologies. Developing countries are responsible for $63 \%$ of GHGs emissions and get hit the hardest, i.e., $78 \%$ of the cost of climate change, and predicted to rise to $87 \%$ by 2035 [3]. For example, people in tropical countries are more exposed to natural disasters, e.g., storms and extreme weather. Poorer living conditions make them fragile to disaster strikes. Common measures of controlling GHG emissions are pricing the emissions and adopting cleaner energy. Even if a price can be offered, it is unlikely to convince developing countries to instantly give up fossil fuel or to pursue nuclear energy while ignoring non-proliferation and nuclear waste. A more acceptable solution, at least in the near future, is circular economy [4] or to reduce emissions without substantial changes in energy infrastructure using intelligent technologies.

Manufacturing, a core of the product provision system and a major source of GHG and other emissions,

\footnotetext{
*Correspondence: baicunw@zju.edu.cn

${ }^{2}$ State Key Laboratory of Fluid Power and Mechatronic Systems, Zhejiang University, Hangzhou 310027, China

Full list of author information is available at the end of the article
}

has substantial influences on both economic and sustainability issues. Years ago, before the topic of Industry 4.0 become the dominating theme of the Hanover Trade Fair, its motto had been "Greentelligence" [5]. The objective is to capture and monitor manufacturing activities and shift them into a greener and more eco-efficient paradigm while holding competing costs [6]. A greener paradigm may offer opportunities for cost reduction and eco-friendly development [7]. Industry 5.0, a new industrial paradigm from the European Commission's consensus has been proposed to strategically plan the production and economic growths accounting for the planetary boundaries and societal goals. But exploiting these opportunities involves more than technological issues, which requires identifying priorities and finding ways to align them with existing infrastructures and technologies [8]. Over the last decade, intelligent technologies have been growing rapidly for increasing production efficiency and flexibility. There are many ways to benefit manufacturing facilities and workplace practices with improved environmental performance [7]. It requires the current manufacturing system to go beyond producing goods and/or services for profit and highlights the importance of long-term service to environmental and societal benefits, including human-centricity, sustainability and resilience $[9,10]$.

Evolving smart manufacturing systems into a greener paradigm in Industry 5.0 era is both timely and critical. The implications of intelligent technologies to green objectives are deemed controversial and the greenness assessment of intelligent technologies also remains to be addressed. In this study, we propose "Greentelligent manufacturing (GIM)" as a novel integrated manufacturing paradigm that uses intelligent techniques as the enabler for green objectives. Various green and 
sustainable objectives are potentially accompanied by intelligent technologies, and the sustainability of intelligent systems should also be assessed and enhanced by green metrics.

\section{Evolution and Framework of Greentelligent Manufacturing}

The evolution of greentelligent manufacturing can be sorted into three stages, including emerging stage, transitional stage, and synergetic stage (Figure 1). At the emerging stage, green manufacturing (GM) and intelligent manufacturing (IM) were proposed separately to some extent despite their overlapped goals, e.g., optimal resource allocation, focusing on sustainability and intelligence, respectively. At the transitional stage, GM and IM start to leverage the merits of each other to address their own goals. At the synergetic stage, GM and IM start to merge with aligned goals and tools designed for the objectives in both paradigms. For the rest of the paper, greentelligent manufacturing (GIM) is referred to as an intelligent, human-centered, and eco-friendly manufacturing paradigm to emerge and lead at the synergetic stage.

The primary goal of greentelligent manufacturing is to integrate intelligent technologies and green methods to achieve superior control, productivity and sustainability in manufacturing systems. Greentelligent manufacturing framework is designed accordingly to encompass a continuously evolving group of methods and materials, from techniques for clean energy generation to the design of green products, as shown in Figure 2. The term '(in)telligent' refers to (1) smart infrastructure, software, and networked solutions for advanced sensor, instrumentation, control technologies and process optimization that implement with the manufacturing environment; (2) information and communication technologies (ICT) developed for real-time monitoring of waste, consumptions and GHG emissions, as well as real-time management of energy, productivity, and costs across facilities [11]. The adaptation of intelligent technologies helps to better reach sustainable objectives while remaining competitive and value-adding to advanced manufacturing sectors.

Our greentelligent manufacturing addresses the term 'green' in several aspects [12]: (1) to deliver greener products by changing industrial processes and product design; (2) to green the manufacturing process by reducing emissions and waste, minimizing natural resource use, and improving the energy and manufacturing efficiency; (3) to assess the greenness of abovementioned intelligent techniques. In the following section, we discuss greentelligent manufacturing in detail organized by enabling mechanisms and supporting tools/methods.

\section{Enabling Mechanisms towards Greentelligent Manufacturing}

\subsection{Change Manufacturing Processes}

\subsubsection{Change the Nature of Process}

Switching from a chemical process to a physical or a biological process often becomes more beneficial for the environment [9]. For example, using a controllable pressure to create the flexible polyurethane foam, rather than a chemical process involving chlorofluorocarbons can reduce GHG emissions [13].

\subsubsection{Advanced Manufacturing Processes}

Intelligent technologies can be used directly to reduce GHG emissions from industrial processes. In the largescale production of hydrogen, GHG emissions are produced as a side product during the steam reforming and heating of reactors. Electrification technology can reduce GHG emissions and offer flexible and compact heat generation [14].

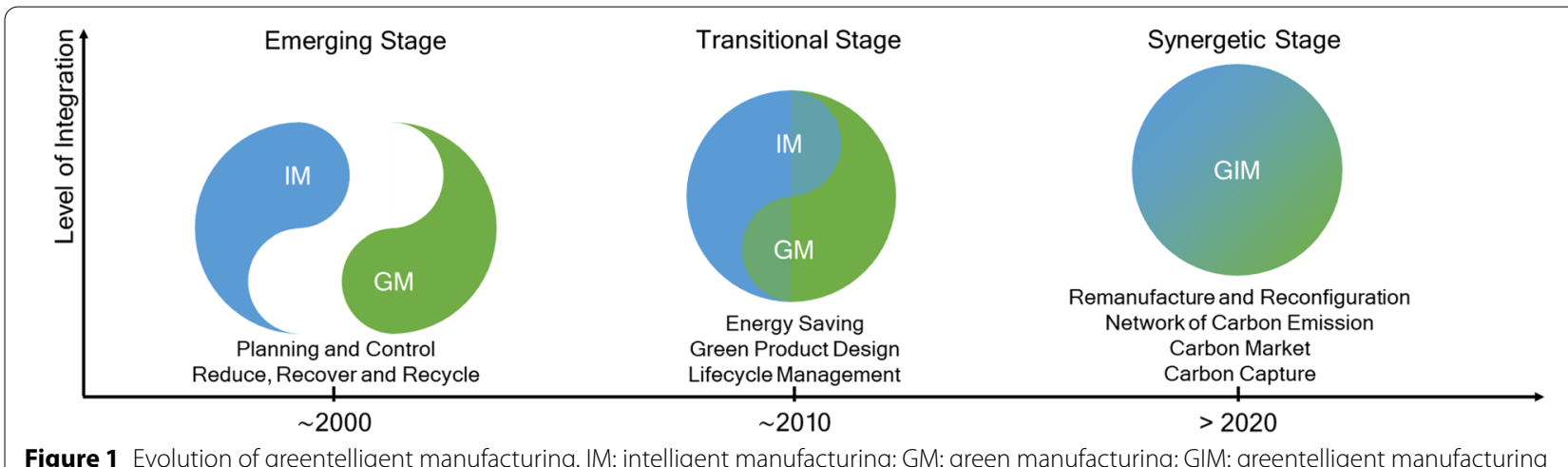

Figure 1 Evolution of greentelligent manufacturing. IM: intelligent manufacturing; GM: green manufacturing; GIM: greentelligent manufacturing 


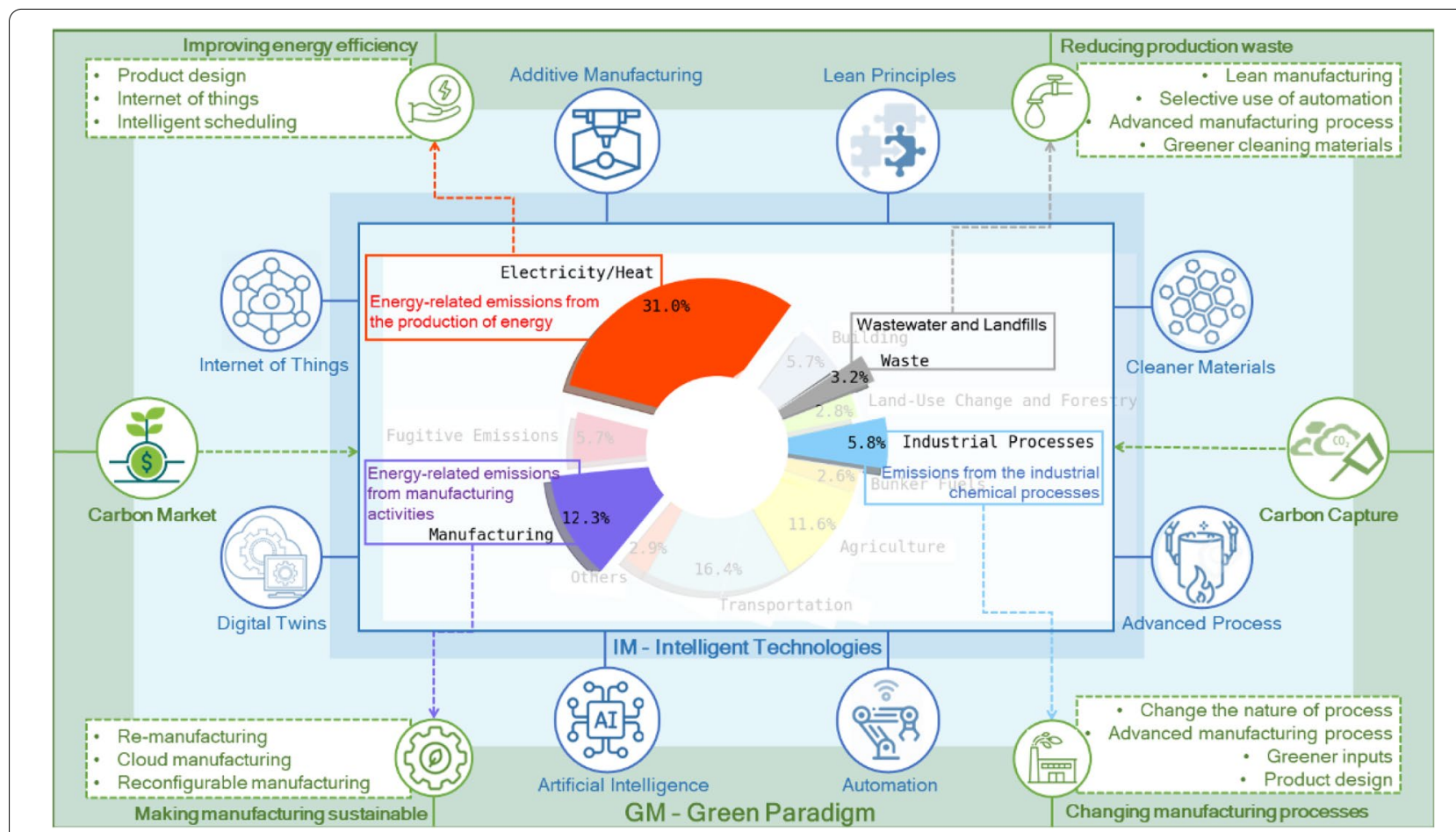

Figure 2 Framework of greentelligent manufacturing

\subsubsection{Greener Inputs}

Both major and minor ingredients which contribute to the production and are not included in the end product are worth changing. As one of the major sources of producing energy with $\mathrm{CO}_{2}$ as a byproduct, fossil fuels are depleting rapidly. There is an urgent need of finding alternative energy from renewable sources, including hydrogen, biobutanol and bioethanol.

\subsubsection{Advanced Product Design}

Intelligent tools, e.g., Autodesk Inventor and Ansys Granta Selector, have been developed to support the design of green alternatives based on the analysis of material properties, traceability, configuration, and environmental impacts. From the analysis, greener materials and production plans can be optimized.

\subsection{Reducing Production Waste}

In order to reduce waste and emissions, IM technologies can be deployed to improve the efficiency and quality in making existing products, thus controlling the amount of waste to be placed.

\subsubsection{Lean Manufacturing}

Lean manufacturing is a fundamental concept to reduce waste in production with assured quality. Creating continuous material flows from customers to suppliers and using tact time and pull system to manage the workflow provide continuous improvement in all stages of a manufacturing process towards zero-waste [15].

\subsubsection{Selective Use of Automation}

Smart sensors and machines take over parts of what humans used to do, which reduces the dependence of manufacturing processes on active human intervention. Automated process control, human-robot collaboration, and numerically controlled machine tools can effectively reduce human errors and defections, thus reducing wastes.

\subsubsection{Advanced Manufacturing Process}

Additive manufacturing (3D printing) makes a physical object from a three-dimensional digital model. Unlike a subtractive process, where only a small percentage of the material goes into the final part, the material wastes in $3 \mathrm{D}$ printing are minimized [16]. 


\subsubsection{Greener Cleaning Materials}

Cleaning is the source of water waste from manufacturing processes. These impacts can partly be reduced by changing inputs from solvents to water- and bio-based cleaners.

\subsection{Improving Energy Efficiency}

Increased adoption of intelligent technologies that combine advanced manufacturing technologies and intelligent efficiency management is promising to help manufacturers reduce facility-level energy intensity [17]. Besides the aforementioned technologies, including advanced manufacturing processes, greener inputs, advanced product design, lean manufacturing, we identified the following IM technologies as additional enablers for improving energy efficiency.

\subsubsection{Equipment and Factory Design}

Greener high-end equipment has been designed to reduce the energy consumption in cutting and grinding. Moreover, a factory can be continuously improved for better energy efficiency, from the aspect of air conditioning, e.g., arranging air circulation fan and optimizing airflow, lighting, and logistics, e.g., minimizing material transportation distance.

\subsubsection{Internet of Things (IoT)}

The increasing capabilities of internet-connected sensors and the associated IoT techniques provide advanced metering and sub-metering solutions, which substantially improve the performance of energy management systems. Some enterprises have implemented a highly digitalized manufacturing system, which monitors and controls the production and energy usage, projecting a $20 \%$ average reduction in energy consumption per industrial facility in 2035 [18].

\subsubsection{Intelligent Scheduling and Artificial Intelligence}

Intelligent scheduling and artificial intelligence help manufacturers unlock energy efficiency from the equipment level to the entire supply chain. For example, the intelligent scheduling process of multiple connected manufacturing systems is modeled for adaptively configuring lines and scheduling the jobs based on the stochastic demands to increase the utility rate of energy [19].

\subsection{Making Manufacturing Sustainable}

Sustainable manufacturing targets to increase operational efficiency, respond to new customers' requirements, and build long-term business viability and success.

\subsubsection{Remanufacturing}

Remanufacturing aims to restore the returned product to full functionality and use it for another lifecycle and has huge potentials for energy and waste reduction. Studies discovered that remanufacturing has the potentials for reducing carbon emissions, improving the product quality, eco-efficiency, and service level [20-22].

\subsubsection{Service-oriented Manufacturing (SOM)}

$\mathrm{SOM}$ aims to share manufacturing capabilities and resources through a cloud platform [23]. SOM offers a solution to leverage the intelligent decision-making capacities from the cloud, to provide the most sustainable and robust options in manufacturing. For instance, Plex Manufacturing Cloud [24] is a software that packages the enterprise resource planner (ERP) as a service (SaaS) help manufacturers to organize their manufacturing process more efficiently and intelligently.

\subsubsection{Reconfigurable Manufacturing}

Reconfigurable manufacturing (RM) was initially designed to enhance responsiveness to unpredictable market changes and recently showed its superiority in managing wastewater and emissions using system reconfiguration. Khezri et al. proposed an optimization model for sustainable operation in a reconfigurable manufacturing environment with mathematical modeling of hazardous waste and emissions [25]. Meanwhile, combining the IoT technologies and artificial intelligence, machine failure can also be detected and inferred earlier in RMS to reduce the defect rate and to improve manufacturing efficiency [26].

\section{Supporting Tool/Methods toward Greentelligent Manufacturing}

4.1 Life Cycle Assessment and Carbon Pricing Strategies Life cycle assessment (LCA) is a standardized approach to evaluating the environmental impacts of a product, process or activity by tracking material and energy usage and waste outputs at every life stage [27]. It is critical to have an accounting of inputs, wastes, and their associated costs at each point in the manufacturing process. The actual efficiency greatly depends on the automation level of this process. The assessment can be enhanced by artificial intelligence to pinpoint costs, particularly track costs back to specific manufacturing processes to project future costs. Advanced ICTs enable the real-time monitoring of $\mathrm{CO}_{2}$ from fuel combustion, and airflow sensing in various parts of the furnaces [28]. Networks of energy 
and $\mathrm{CO}_{2}$ emission can be designed using IoT to enhance services in the manufacturing process and to address the complex energy consumptions [29].

Greentelligent manufacturing can leverage carbon emission as an ingredient to design the entire supply chain. In a consumer viewpoint, producers are not directly motivated to reduce emissions, while consumers, instead, should assume responsibility for choosing the best strategies and policies by showing a preference for eco-friendly producers. IoT techniques and digital supply chain connect the entire supply chain, from raw material suppliers to customers and pricing the products considering the environmental costs to morph the market dynamically. Other pricing strategies to encourage greener development are carbon taxes and emissions trading systems (ETS).

A carbon tax directly sets a price on carbon by defining a tax rate on $\mathrm{CO}_{2}$ emissions. ETS caps the total level of greenhouse gas emissions and allows those industries with low emissions to sell their extra allowances to larger emitters. Compared to carbon tax, ETS of a carbon tax is not often pre-defined but the carbon price negotiated among enterprises. This enterprise-level carbon market helps to reach the required emission reduction target by keeping the emitters reweighing the investment costs of greener technologies and carbon purchase. More than 40 countries and 20 cities, states and provinces already use carbon pricing mechanisms, with more planning to implement them in the future [30].

\subsection{Carbon Capture and Storage}

All the aforementioned methods aim to reduce carbon emission, either in a short or long term. Carbon capture and storage (CCS) is identified as an effective technique for compensating the existing $\mathrm{CO}_{2}$ emissions. Norway was the first nation to take CCS seriously for the implementation of CCS devices on all fossil-fired power plants and declared CCS would be Norway's "Moon mission" [31]. Recent developments in polymeric membranes have successfully achieved carbon capture on a demonstration scale [32].

CCS has not yet been widely deployed on a commercial scale owing to a variety of technical, economic and political challenges, which makes the prospects for CCS technologies are at a complete standstill in many countries. Two main cost drivers to CCS: 1) energy penalty to separate and compress the $\mathrm{CO}_{2}$ (costs due to the loss of power generation efficiency), and 2) capital costs (costs required to build, install and operate the equipment). There are several benefits gained from intelligent technologies to address the challenges in CCS: (1) Use digital twins to evaluate electrical load and energy consumptions of
CCS technologies. (2) Use the IoT to monitor and control plant contribution to $\mathrm{CO}_{2}$ emissions. Vatopoulos and Tzimas have designed a mathematical model as a digital twin to evaluate three CCS technologies [33], in terms of, oxy-combustion, amine scrubbing, and chemical looping in a cement-making process. In comparison, the chemical looping shows a lower energy consumption than amine scrubbing with $18 \%$ increased efficiency.

\section{Conclusions}

This highlight article proposes greentelligent manufacturing as a novel integrated manufacturing paradigm towards Industry 4.0 and Industry 5.0, not only for prioritizing green technology innovations but also for achieving a smoother transition to a greener future. A framework, critical technical enablers, and promising research directions are discussed in detail. At present, manufacturing industry is at the transitional stage where green manufacturing and intelligent manufacturing technologies are conceptualized and experimented with to better achieve each other's goals. With increasing awareness of greener development and the popularization of intelligent technologies, it is foreseeable that greentelligent manufacturing will become a promising manufacturing paradigm that addresses the issues in eco-friendly, human-centric and economic development of our society.

Challenges remain in realizing the greentelligent manufacturing. Compared to the advanced manufacturing technologies, the advantages of greentelligent manufacturing are mostly the value added to the society and environment which will be visible in the long run. To promote greentelligent manufacturing, a comprehensive assessment tool for green technologies for different industrial compositions and technology readiness levels is critical but missing. In future work, authors will explore the life cycle assessment to dynamically evaluate the carbon footprint and greenness of a product. Moreover, the additional emissions from the intelligent equipment and systems, including controllers, sensors and chips, will be accounted to gain more actionable insights into greentelligent manufacturing.

\section{Acknowledgements}

The authors sincerely thanks to the researchers at the Institute of Industrial Engineering, Zhejiang University for their critical discussions during manuscript preparation.

\section{Authors' Information}

Xingyu Li, born in 1992, is currently a Research Investigator at Department of Mechanical Engineering, University of Michigan, USA. He received his doctoral degree from University of Michigan, USA. His main research interests include manufacturing systems, operation research, deep learning, artificial intelligence, and optimization. 
Baicun Wang, born in 1990, is currently a Research Professor at the State Key Laboratory of Fluid Power and Mechatronic Systems, Zhejiang University, China. He received his doctoral degree from Zhejiang University, China, and worked as Post-doc Researcher at Tsinghua University, Chinese Academy of Engineering, China, and the University of Michigan, USA. His main research interests include human-cyber-physical systems (HCPS), intelligent manufacturing, industrial and systems engineering.

Tao Peng, born in 1984, is currently an Associate Professor at State Key Laboratory of Fluid Power and Mechatronic Systems, Zhejiang University, China. He received his bachelor and master degrees from Xian Jiaotong University, China, and doctoral degree from the University of Auckland, New Zealand. His research interests include smart sustainable manufacturing, data analytics and intelligence in collaborative manufacturing, smart production management and decision support.

Xun Xu, born in 1959, ASME/EngNZ Fellow, is currently a Chair Professor at the Department of Mechanical Engineering, the University of Auckland, New Zealand. He received his doctoral degree from the University of Manchester, UK. His research interests include smart and interoperable manufacturing, advanced technologies in Industry 4.0, cyber-physical systems, and cloud manufacturing.

\section{Authors' Contribution}

XL: Methodology; Formal analysis; Writing—original draft. BW: Conceptualization; Methodology; Investigation; Writing — review and editing; Supervision. TP: Conceptualization; Resources; Writing_original draft. XX: Writing_review and editing. All authors read and approved the final manuscript.

\section{Funding}

Supported by Zhejiang Provincial Natural Science Foundation of China (Grant No. LY19E050019), Zhejiang Provincial Soft Science Research Project (Grant No. 2022C35040) and Zhejiang University "Hundreds of Talents" Program (Grant No. 0020886).

\section{Competing Interests}

The authors declare no competing financial interests.

\section{Author Details}

'Department of Mechanical Engineering, University of Michigan, Ann Arbor, MI 48109, USA. ${ }^{2}$ State Key Laboratory of Fluid Power and Mechatronic Systems, Zhejiang University, Hangzhou 310027, China. ${ }^{3}$ Department of Mechanical Engineering, The University of Auckland, Auckland, New Zealand 1010.

\section{Received: 11 August 2021 Accepted: 15 November 2021}

Published online: 02 December 2021

\section{References}

[1] ClimateWatch, 2020. Historical GHG Emissions. [2021-06-24]. https:// www.climatewatchdata.org/ghg-emissions?end_year=2018\&start_ year $=1990$.

[2] TA ukker, A De Koning, R Wood, et al. EXIOPOL-development and illustrative analyses of a detailed global MR EE SUT/IOT. Economic Systems Research, 2013, 25(1): 50-70.

[3] W Nordhaus. Integrated assessment models of climate change. NBER Reporter, 2017: 16-20.

[4] M Geissdoerfer, P Savaget, N M Bocken, et al. The Circular Economy-A new sustainability paradigm? Journal of Cleaner Production, 2017, 143: 757-768.

[5] U Sendler. The internet of things: Industrie 4.0 unleashed. Springer, 2017.

[6] A M Deif. A system model for green manufacturing. Journal of Cleaner Production, 2011, 19(14):1553-1559.

[7] M Atlas, R Florida. Green manufacturing. Handbook of Technology Management, 1998: 1385-1393.

[8] TC Heller, P R Shukla. Development and climate: Engaging developing countries. Beyond Kyoto: Advancing the international effort against climate change, 2003: 111-140.

[9] M Breque, L De Nul, A Petridis. Industry 5.0: towards a sustainable, humancentric and resilient European industry. Luxembourg, LU: European Commission, Directorate-General for Research and Innovation, 2021.
[10] J Zhou, Y Zhou, B Wang, et al. Human-cyber-physical systems (HCPSs) in the context of new-generation intelligent manufacturing. Engineering, 2019, 5(4): 624-636.

[11] S Nimbalkar, W Guo, C Petri, et al. Smart manufacturing technologies and data analytics for improving energy efficiency in industrial energy systems. Oak Ridge National Laboratory, Knoxville, TN Wei Guo, Oak Ridge National Laboratory, 2017.

[12] R Kumar, P Rao. Green manufacturing technology-solution for environmental impact and waste. Sustainable Development, 2018, 4(12): 532-535.

[13] J Yang, Y Ye, X Li, et al. Flexible, conductive, and highly pressure-sensitive graphene-polyimide foam for pressure sensor application. Composites Science and Technology, 2018, 164: 187-194.

[14] STWismann, J S Engbæk, S B Vendelbo, et al. Electrified methane reforming: A compact approach to greener industrial hydrogen production. Science, 2019, 364(6442): 756-759.

[15] W D Leong, H L Lam, W P Q Ng, et al. Lean and green manufacturing-A review on its applications and impacts. Process Integration and Optimization for Sustainability, 2019, 3(1): 5-23.

[16] T Campbell, CWilliams, O Ivanova, et al. Could 3D printing change the world. Technologies, Potential, and Implications of Additive Manufacturing, Atlantic Council, Washington, DC, 3, 2011.

[17] R N Elliott. Energy efficiency and industry: The national trend. Washington DC: American Council for an Energy-Efficient Economy, 2016, http:// aceee.org/blog/2015/12/energyefficiency-and-industry.

[18] A Salam. Internet of things in sustainable energy systems. In: Internet of Things for Sustainable Community Development, Springer, Cham, 2020: 183-216.

[19] X Li, A E Bayrak, B I Epureanu, et al. Real-time teaming of multiple reconfigurable manufacturing systems. CIRP Annals, 2018, 67(1): 437-440.

[20] X Zhang, X Ao, W Cai, et al. A sustainability evaluation method integrating the energy, economic and environment in remanufacturing systems. Journal of Cleaner Production, 2019, 239: 118100.

[21] W Kerr, C Ryan. Eco-efficiency gains from remanufacturing: A case study of photocopier remanufacturing at Fuji Xerox Australia. Journal of Cleaner Production, 2001, 9(1): 75-81.

[22] X Li, N Li, I Kolmanovsky, et al. Stochastic model predictive control for remanufacturing system management. Journal of Manufacturing Systems, 2021, 59: 355-366.

[23] B H Li, L Zhang, S L Wang, et al. Cloud manufacturing: a new serviceoriented networked manufacturing model. Computer Integrated Manufacturing Systems, 2010, 16(1): 1-7.

[24] Plex Systems Inc. Plex manufacturing cloud. https://www.plex.com/.

[25] A Khezri, H H Benderbal, L Benyoucef. A sustainable reconfigurable manufacturing system designing with focus on environmental hazardous wastes. 201924th IEEE International Conference on Emerging Technologies and Factory Automation (ETFA), September, 2019: 317-324.

[26] B I Epureanu, X Li, A Nassehi, et al. Self-repair of smart manufacturing systems by deep reinforcement learning. CIRP Annals, 2020, 69(1): 421-424.

[27] TS Harding. Life cycle assessment as a tool for Green manufacturing education. Materials Engineering, 2004: 62.

[28] L Scholz, A O Perez, B Bierer, et al. Miniature low-cost carbon dioxide sensor for mobile devices. IEEE Sensors Journal, 2017, 17(9): 2889-2895.

[29] W Liu, T Peng, R Tang, et al. An Internet of Things enabled model-based approach to improving the energy efficiency of aluminum die casting processes. Energy, 2020, https://doi.org/10.1016/j.energy.2020.117716.

[30] M Wara. Is the global carbon market working? Nature, 2007, 445(7128): 595-596.

[31] K Buhr, A Hansson. Capturing the stories of corporations: A comparison of media debates on carbon capture and storage in Norway and Sweden. Global Environmental Change, 2011, 21(2): 336-345.

[32] Y Han, W W Ho. Recent advances in polymeric membranes for $\mathrm{CO} 2$ capture. Chinese Journal of Chemical Engineering, 2018, 26(11): 2238-2254.

[33] M Pérez-Fortes, J A Moya, KVatopoulos, et al. CO2 capture and utilization in cement and iron and steel industries. Energy Procedia, 2014, 63: 6534-6543 